\title{
Recurrent secondary postpartum haemorrhage due to endometritis: requires 18 units blood transfusion
}

\author{
Mamta Sharma, Deepti Maheshwari*
}

\begin{abstract}
Department of Obstetrics and Gynecology, J. K. Lon Mother and Child Hospital, Government Medical College, Kota,
\end{abstract} Rajasthan

Received: 26 March 2016

Revised: 01 May 2016

Accepted: 13 May 2016

\section{*Correspondence:}

Dr. Deepti Maheshwari,

E-mail: maheshwarideepti11@gmail.com

Copyright: (c) the author(s), publisher and licensee Medip Academy. This is an open-access article distributed under the terms of the Creative Commons Attribution Non-Commercial License, which permits unrestricted non-commercial use, distribution, and reproduction in any medium, provided the original work is properly cited.

\begin{abstract}
Postpartum hemorrhage (PPH) represents a serious problem for women and obstetricians. Because of its association with haemorrhagic shock and predisposition to disseminated coagulopathy, it is a leading cause of maternal deaths worldwide. Furthermore, the jeopardy of PPH is rising with the secondary form of PPH occurring between 24 hours and 6 weeks postpartum, when women are already discharged home. The causes of this pathology are severe inflammation (endometritis) inherited coagulation disorders, consumptive coagulopathy, and retained products of conceptions. Others are of rare occurrence, such as vessel subinvolution (VSI) of the placental implantation site, uterine artery pseudo aneurysm, or trauma.
\end{abstract}

Keywords: PPH, haemoglobin, White blood cells, Ultra sonography

\section{INTRODUCTION}

Postpartum hemorrhage (PPH) represents serious problem for women and obstetricians. Because of its association with hemorrhagic shock and predisposition to disseminated coagulopathy, it is a leading cause of maternal deaths worldwide. ${ }^{1}$ The severity of PPH is potentiated by the fact that it is not specifically associated with the mode of delivery (vaginal vs. caesarean section). Furthermore, the jeopardy of $\mathrm{PPH}$ is rising with the secondary form of PPH (abnormal excessive bleeding from the birth canal, mostly uterus, occurring between 24 hours and 6 weeks postpartum), when women are already discharged home. In general, the incidence of PPH is approximately $5 \%-20 \%$ of labors, with the highest rates in developing countries. ${ }^{1,2}$

The common etiologies such as uterine hypotony/atony(most common cause of primary $\mathrm{PPH}$ ), severe inflammation (endometritis), retained products of conceptions (most common cause of secondary $\mathrm{PPH}$ ), placental abruption, transverse or classical caesarean delivery, manual placental extraction, inherited coagulation disorders, consumptive coagulopathy. ${ }^{4}$ Others are of sporadic occurrence and play an important role such as vessel subinvolution (VSI) of the placental implantation site, trauma, or uterine artery pseudo aneurysm, where the affected vessel wall does not allow adequate contraction and involution.,

As mentioned previously, the wicked situation occurs when PPH is presented in its secondary form, even if it affects only $1-2 \%$ of postnatal women. The primary danger for patient is that bleeding in the majority occurs between 1 and 2 weeks after delivery, when patient is often home and unaware that the hemorrhage is significant and potentially life threatening. ${ }^{7,8}$ In this paper, we present a rare form of recurrent secondary postpartum haemorrhage in a woman after uncomplicated vaginal delivery. 


\section{CASE REPORT}

A 33year old female G4P3L3 delivered a full term male child delivered vaginally at $\mathrm{CHC}$ hospital, where she was transfused one unit blood after delivery and discharged on the 6th day post-partum, patient was admitted 4 times with complain of profuse vaginal bleeding at $\mathrm{CHC} /$ other hospital for which conservative management was done with uterotonics along with 14 units of blood transfusion and once platelet was given and discharged home every time with controlled bleeding, physical and pelvic USG examination failed to reveal the cause of bleeding. On $39^{\text {th }}$ day of postpartum, she was referred to our hospital with complaints of severe vaginal bleeding on examination general condition of patient was poor with systolic blood pressure of $70 \mathrm{mmHg}$ with feeble pulse patient was on dopamine, extremity were pale, abdomen was soft and there was packing in situ per virginal, on investigation her $\mathrm{Hb}$ was 6 gm/dl,WBC13000 ,coagulation profile was within normal limit, USG Pelvis repeated which showed PID with normal colour Doppler ,patient was managed symptomatically with broad spectrum antibiotics and 4 units of blood transfusion after discussion hysterectomy was advised and total abdominal hysterectomy with right salpingooophorectomy was done, left ovary was found normal, uterus was normal in size but congested, the post-operative recovery was uneventful and patient was discharged, histopathology reports revealed chronic nonspecific cervicitis, endometritis with right ovarian cystic follicle, no retained placenta or placental accrete was noted.

\section{DISCUSSION}

Postpartum hemorrhage is a serious obstetrics emergency. The bleeding after labor can occur within 24 hours (primary form of $\mathrm{PPH}$ ) or, later, from 24 hours after delivery until 6 weeks postpartum (secondary form of PPH). In general, for mild PPH, a blood loss $>500 \mathrm{ml}$ and a severe blood loss $>1000 \mathrm{ml}$ are considered after spontaneous delivery or above $1000 \mathrm{ml}$ in cesarean section. $^{3,9}$

Unlikely the definition of primary PPH, there is no clear or standard definition for quantity of blood loss associated with secondary PPH and clinical expression of this definition vary from increased lochia to massive bleeding. The etiology of secondary PPH is diverse and management is dependent on identifying the cause and tailoring treatment appropriately. The majority of cases of secondary PPH are associated with minor morbidities but many still requires readmission to hospital use of antibiotics and surgical intervention. In more extreme cases major morbidity may require hysterectomy, arterial ligation or radiological intervention. ${ }^{10}$ Despite the use of all available interventions, maternal death may still result from massive secondary PPH. The major cause of secondary PPH is subinvolution of the uterus. This result in failure of obliteration of blood vessels underlying the placental site, leading to prolonged bleeding. The two main causes of this are infection and inflammation (Endometritis) and retained placental tissue. Endometritis is more common following prolonged rupture of membranes, prolonged labor, emergency $\mathrm{C}$-section or with a retained placenta requiring manual removal. A history of offensive lochia, maternal pyrexia and uterine tenderness is often present and retained placental tissue is more common in women with a previous history of retained placenta or if there were concerns at the time of delivery of incomplete placenta and/or membranes. Differentiation between the two causes is often difficult and both conditions may co-exist. When the bleeding is more severe, retained placental fragments are often noted. These patients usually require $\mathrm{D}$ and $\mathrm{C}$ to controlled haemorrhage. Sepsis causing acute endometritis is reported as a cause of PPH and haemorrhage may be followed by ascending infections.

It is relatively uncommon in modern obstetric practice in the developed world and may be due to a variety of organisms. Its incidence is increased following emergency cesarean section. It accounted for less than $5 \%$ of cases of delayed PPH in one series. ${ }^{11}$ Subinvolution of the uterus is sometimes due to infection. The cause of hich, particularly late puerperal period, might be C.trachomatis. Endometritis is likely to play a significant role in many cases of secondary PPH and majority of women are prescribed antibiotics. In a 3-year study of almost 20,000 women, 132 women $(0.69 \%)$ had a secondary PPH, and $97 \%$ of these were treated with antibiotics. ${ }^{12}$

However, only $75 \%$ of these women had microbiological specimens collected; of these, a positive culture was obtained in only $13.5 \%$.In a similar observational study of 83 women, $45 \%$ presented with pyrexia and 64 had bacteriological swabs taken, of which only $12.5 \%$ were positive. Organisms identified included group B streptococcus, Bacteroides sp., Escherichia coli, Clostridium perfringens and group D streptococcus. Despite the lack of evidence to support the presence of a specific bacterial pathogen, $92 \%$ of the women received antibiotics. ${ }^{7}$ Although the incidence of secondary PPH is very low, therapeutic management is close to primary PPH, requires coordination and multidisciplinary care, aiming the immediate hemodynamic stabilization of the patient, depleted blood volume, and development of coagulopathy. Treatment usually falls into one of two options: surgical evacuation of the uterine cavity or medical treatment. ${ }^{13}$

Often, blood and plasma unit transfusion is required. Speculum examination of the cervix and the lower genital tract to exclude possible lacerations is obligatory. Furthermore, uterine ultrasound is mandatory to exclude a possibility of the retained placental tissue. ${ }^{14}$ In differential diagnosis, it is necessary to exclude vaginal bleeding because of the severe endometritis, retained placental tissue, or gestational trophoblastic disease, 
where laboratory findings of inflammatory markers (e.g., CRP, leucocytes), positive blood and vaginal cultures, elevated $\beta H C G$ levels, and expert ultrasound examination are essential for the adequate diagnosis. ${ }^{14,15}$

\section{CONCLUSION}

Endometritis is one of the rare forms of secondary PPH and is frequently undiagnosed by clinicians. In our case Neutrophilia and histological confirmation of endometritis and cervicitis confirms the diagnosis. However this is done mainly after the hysterectomy. Futhermore, we believe that this type of secondary PPH is of idiopathic than of iatrogenic cause and there are not known predictive factors for this pathology. The obstetricians and caregivers are demanding for an early recognition of severe forms of secondary $\mathrm{PPH}$, thus emphasizing on targeted therapy and may preserve women's fertility.

Funding: No funding sources

Conflict of interest: None declared

Ethical approval: Not required

\section{REFERENCES}

1. Carroli G, Cuesta C, Abalos E, Gulmezoglu AM. Epidemiology of postpartum haemorrhage: a systematic review. Best Pract Res Clin Obstet Gynaecol. 2008;22:999-1012.

2. Khan KS, Wojdyla D, Say L, Gülmezoglu AM, Van Look PF. WHO analysis of causes of maternal death: a systematic review. Lancet. 2006;367:1066-74.

3. Knight M, Callaghan WM, Berg C, Alexander S, Bouvier-Colle $\mathrm{MH}$, Ford JB, et al. Trends in postpartum hemorrhage in high resource countries: a review and recommendations from the International Postpartum Hemorrhage Collaborative Group. BMC Pregnancy Childbirth. 2009;9:55.

4. Fong A, Leake J, Pan D, Ogunyemi D. Demographic, institutional and obstetrical risk factors for postpartum haemorrhage mortality. J Obstet Gynaecol. 2010;30:470-5.
5. Andrew AC, Bulmer JN, Wells M, Morrison L, Buckley CH. Subinvolution of the uteroplacental arteries in the human placental bed. Histopathology. 1989;15:395-405.

6. Weydert JA, Benda JA. Subinvolution of the placental site as an anatomic cause of postpartum uterine bleeding: a review. Arch Pathol Lab Med. 1994;130:1538-42.

7. King PA, Duthie SJ, Dong ZG, Ma HK. Secondary postpartum haemorrhage. Aust N Z J Obstet Gynaecol.1989;29:394-8.

8. Hoveyda F, MacKenzie IZ. Secondary postpartum haemorrhage: incidence, morbidity and current management. BJOG. 2001;108:927-30.

9. Bais JM, Eskes M, Pel M, Bonsel GJ, Bleker OP. Postpartum haemorrhage in nulliparous women: incidence and risk factors in low and high risk women. A Dutch population-based cohort study on standard $(>$ or $=500 \mathrm{ml})$ and severe $(>$ or $=1000 \mathrm{ml})$ postpartum haemorrhage. Eur J Obstet Gynecol Reprod Biol. 2004;115:166-72.

10. Ledee N, Ville Y, Musset D, Mercier F, Frydman R, Fernandez H. Management in intractable obstetric haemorrhage: an audit study on 61 cases. Eur J Obstet Gynecol Reprod Biol. 2001;94:189-96.

11. 11.Khong TY, Khong TK. Delayed postpartum hemorrhage: a morphologic study of causes and their relation to other pregnancy disorders. Obstet Gynecol 1993;82:17-22.

12. Hoveyda F, MacKenzie IZ. Secondary postpartum haemorrhage: incidence,morbidity and current management. BJOG. 2001;108(9):927-30.

13. Neill A, Thornton S. Secondary postpartum haemorrhage.J Obstet Gynaecol. 2002;22:119-122.

14. Zubor P, Szunyogh N, Dokus K, Scasny P, Kajo K, Galo S, et al. Application of uterotonics on the basis of regular ultrasonic evaluation of the uterus prevents unnecessary surgical intervention in the postpartum period. Arch Gynecol Obstet. 2010;282:261-7.

15. Mulic-Lutvica A, Eurenius K, Axelsson O. Uterine artery Doppler ultrasound in postpartum women with retained placental tissue. Acta Obstet Gynecol Scand. 2009;88:724-8.

Cite this article as: Sharma M, Maheshwari D.

Recurrent secondary postpartum haemorrhage due to endometritis: requires 18 units blood transfusion. Int J Reprod Contracept Obstet Gynecol 2016;5:205860 . 